\title{
Integrasi Pendidikan Al-Qur'an dan Budaya Alam Minangkabau Dalam Setting Pembelajaran Daring
}

\author{
Nora Susilawati ${ }^{1}$, Emizal Amri ${ }^{2}$, Junaidi Junaidi ${ }^{3}$, Reno Fernandes ${ }^{4}$ \\ Program Studi Pendidikan Sosiologi, Universitas Negeri Padang
}

E-mail: norasusilawati@fis.unp.ac.id, emizalamri@fis.unp.ac.id, junaidiunp@ fis.unp.ac.id, $\underline{\text { renofernandes@ fis.unp.ac.id }}$

\begin{abstract}
Abstrak
Perkembangan teknologi informasi yang membawa kepada zaman keterbukaan bisa saja membawa dampak buruk bagi generasi muda di Indonesia. Pengaruh negatif dari keterbukaan tersebut dapat berupa penyimpangan perilaku dan gaya hidup. Sebagai antisipasinya sistem pendidikan di Indonesia menyediakan pendidikan karakter. Dalam kurikulum 2013 pendidikan karakter diselenggarakan dengan cara pengintegrasian nilai-nilai karakter bangsa dengan matapelajaran yang ada di Sekolah Menengah Atas. Di Sumatera Barat pengintegrasian pendidikan karakter tersebut dilaksanakan dengan integrasi pendidikan Al-Qur'an dan Budaya Alam Minangkabau dengan matapelajaran Sosiologi. Implementasi program pendidikan karakter di Sumatera Barat ternyata belum mencapai hasil yang maksimal. Data penelitian menunjukkan masih banyak Guru-guru di Sumatera Barat yang belum bisa melaksanakan program pengintegrasian. Dengan demikian maka pelatihan pengintegrasian ini penting dilaksanakan. Metode yang dipakai adalah Seminar dan Workshop. Pengabdian dapat dikatakan berhasil karena $83 \%$ peserta kegiatan berhasil membuat Rencana Pelaksanaan Pembelajaran, Media dan Materi ajar sosiologi terintegrasi dengan pendidikan AlQur'an dan Budaya Alam Minangkabau.
\end{abstract}

Kata kunci: Budaya alam minangkabau, Integrasi, Pendidikan karakter, Pendidikan al-qur'an

\section{Abstrac}

The development of information technology that has led to the era of openness can harm the younger generation in Indonesia. The negative effect of this openness can be in the form of behavior and lifestyle deviations. As an anticipation, the education system in Indonesia provides character education. The 2013 curriculum for character education is carried out by integrating the values of national character with existing subjects in high schools. In West Sumatra, the integration of character education is integration with the integration of Al-Qur'an education and Minangkabau Natural Culture with Sociology subjects. The implementation of the character education program in West Sumatra has not yet achieved maximum results. Research data shows there are still many teachers in West Sumatra who have not been able to implement the integration program. Thus, it is important that this integration training be carried out. The methods used are seminars and workshops. Community service can be said to be successful because $83 \%$ of the participants in the activity succeeded in making Learning Implementation Plans, Media and Sociology Materials integrated with the education of the Qur'an and Minangkabau Natural Culture.

Keyword: Minangkabau natural culture, integration, character education, al-quran education

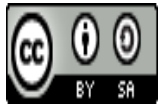

Received: 25 September $2020 \quad$ Revised: 28 September $2020 \quad$ Available Online: 29 September 2020 


\section{Pendahuluan}

Abad 21 ditandai dengan hadirnya era yang disebut dengan Revolusi Industri 4.0 (Fernandes, 2019). Situasi pada abad 21 sering kali diidentikan dengan masyarakat informasi yang ditandai oleh munculnya fenomena masyarakat digital dan abad yang penuh dengan keterbukaan atau abad globalisasi. Akibatnya masyarakat didunia mengalami perubahan-perubahan yang fundamental pada sistem dan struktur masyarakat. Revolusi industri 4.0 yang dengan ciri-ciri perkembangan teknologi informasi yang pesat mengakibatkan lahirnya Generasi baru yang disebut oleh (Prensky, 2001a) dengan digital native yaitu generasi yang lahir dan dibesarkan dalam lingkungan teknologi digital. Lebih lanjut (Prensky, 2001b) menyatakan digital native memiliki karakter berjejaring/koloboratif, multitasking, hypertext, banyak tahu namun dankal secara ontologis.

Pengkategorian digital native menurut (Li, Wang, \& Lei, 2020) dapat dilakukan berdasarkan usia generasi digital yaitu usia dan aksesibilitas. Literatur yang menyatakan bahwa usia menjadi landasan pengelompokan digital native dan digital imigran dikemukan oleh (Prensky, 2001a) (O'Bannon \& Thomas, 2014); (Bowe \& Wohn, 2015). Lebih lanjut Pengkategorian antara digital native dengan digital imigran Menurut (Ransdell, Kent, Gaillard-Kenney, \& Long, 2011) dapat dilihat dari 4 kategori generasi diantaranya: milenium, lahir pada 1982+; generasi X, lahir 1982-1971; boomer muda, 1972-1961; dan boomer yang lebih tua, 1962-1951. Generasi milenial lebih cenderung disebut dengan digital native dan generasi sebelumnya disebut sebagai digital imigrant.

Di indonesia keberadaan genarasi dengan kategori digital native seperti yang dibicarakan diatas memiliki porsi yang dominan bahkan kehadiran generasi ini yang disebut sebagai bonus demografi (Subandowo, 2017). Bonus demografi merupakan peluang Indonesia untuk menjadi negara maju karena 70 persen jumlah penduduknya berada pada usia yang produktif (Dewi, Listyowati, \& Napitupulu, 2018). Pada sisi lain keberadaan generasi muda yang dominan merupakan tantangan besar bagi sebuah negara, bahkan jika tidak terkelola dengan baik bisa menjadi bencana demografi bagi sebuah bangsa (Azoulay, Ding, \& Stuart, 2007).

Perkembangan teknologi informasi yang membawa kepada zaman keterbukaan bisa saja membawa dampak buruk bagi generasi muda di Indonesia (Fajarini, 2014). Pengaruh negatif dari keterbukaan tersebut dapat berupa penyimpangan perilaku dan gaya hidup (F. N. Rosyidah \& Nurdin, 2018). Adapun fenomena perilaku menyimpang tersebut seperti narkoba, LGBT, seks bebas yang ditakutkan berkembang di Indonesia (S. K. Rosyidah, 2017). Berdasarkan bahasan peluang dan tantangan abad 21 seperti yang dibicarakan pada paragraf diatas dapat ditarik kesimpulan bahwa abad ke-21 membutuhkan sumberdaya manusia yang berkualitas yang dihasilkan oleh institusi pendidikan. Tuntutan-tuntutan yang serba baru tersebut meminta berbagai terobosan dalam berfikir, penyusunan konsep, dan tindakan-tindakan. Dengan kata lain diperlukan suatu paradigma baru dalam menghadapi tantangan-tantangan yang baru untuk mampu beradaptasi dengan dunia baru tersebut (Kristiawan, 2016).

Menyikapi fenomena tersebut sistem pendidikan di Indonesia telah mempersiapkan diri. Indonesia mempersiapkan Indonesian Partnership for 21 Century Skill Standard sebagai standar dalam mengelola pendidikan (Puspito, 2017). Pembelajaran Abad 21 merupakan pondasi dalam pelaksanaan pendidikan di Indonesia. Pembelajaran abad 21 menjadi roh dalam kurikulum pendidikan di Indonesia. dalam kurikulum yang digunakan oleh pendidikan dasar dan menengah menekankan pada pengembangan keterampilan 4C diantaranya Critical-Thinking and Problem-Solving Skills, (Communication and Collaboration Skills, (c) Creativity and Innovation Skills), literasi teknologi informasi dan komunikasi, serta penguatan pendidikan karakter (Fernandes, 2019).

Salah satu topik yang manarik dikaji dalam pembelajaran Abad 21 adalah penguatan pendidikan karakter. Pendidikan karakter merupakan proses menanamkan kebiasaan baik melalui institusi pendidikan untuk membentuk peserta didik yang mampu bersikap dan bertindak berdasarkan nilai-nilai yang dijunjung tinggi dalam masyarakat (Depiyanti, 2014) Sejatinya pendidikan karakter di Indonesia telah 
dilaksanakan dengan banyak cara dan secara tegas dinyatakan dalam kurikulum pendidikan nasional. Salah satu caranya adalah pendidikan karakter berbasis sosial budaya (Priyatna, 2017).

Pendidikan karakter berbasis sosial budaya telah dilaksanakan dengan baik diseluruh Indonesia. dalam penyelenggaraan pendidikan karater tersebut juga mengalami perubahan sebagai contoh pendidikan karakter pada masa kurikulum KTSP dilaksanakan dengan matapelajaran muatan lokal. Contoh kasus di Sumatera Barat dilaksankanan dengan mata pelajaran Budaya Alam Minangkabau (Agustina, 2012). Dalam perkembangan penyelenggaraan pendidikan karakter, pergantian kurikulum tingkat satuan pendidikan (KTSP) menjadi Kurikulum 2013 membawa dampak hilangnya Muatan Lokal sebagai mata pelajaran di Sekolah. Konsekuensi dari perubahan kebijakan tersebut hilangnya mata pelajaran Budaya Minangkabau pada Sekolah Formal di Sumatera Barat. Kondisi ini membawa lahirnya Peraturan Gubernur Sumatera Barat Nomor 73 Tahun 2012 tentang Petunjuk pelaksanaan pendidikan karakter pada sekolah/madrasah. Peraturan tersebut memberikan landasaran pelaksanaan pendidikan karakter berbasis sosial budaya yang menyesuaikan dengan kurikulum pendidikan nasional 2013. Selanjutnya pendidikan karakter dilaksanakan dengan mengintegrasikan nilai Alquran dan Budaya Minangkabau dengan matapelajaran di sekolah formal (Junaidi, Susilawati, Fernandes, Sylvia, \& Putra, 2020).

Berdasarkan penelitian (Eka Putri \& Fernandes, 2019) penyelenggaraan integrasi pendidikan AlQur'an dan Budaya Alam Minangkabau di Sumatera Barat masih jauh dari yang diharapkan. Salah satu permasalahannya adalah kurangnya pemahaman guru dalam membuat perencanaan dan melaksanakan pembelajaran terintegrasi tersebut. Kondisi penyelenggaran pendidikan karakter ini diperparah dengan hadirnya wabah Covid-19 di Indonesia.

Pandemi COVID-19 mendatangkan masalah baru bagi sistem pendidikan di Indoensia. Langkah Social Distancing yang berujung pada penutupan sekolah pada tingkat dasar hingga perguruan tinggi. Menurut (Viner et al., 2020) penutupan sekolah diberbagai belahan negara didunia dinilai sangat efektif mengurangi laju perkembangan penyebaran Covid-19. Namun pada sisi lain agenda penutupan sekolah tersebut juga diprediksi akan mempengaruhi keberlangsungan institusi pendidikan. Pola pembelajaran disekolah dan perguruan tinggi juga ikut berubah, yang sebelumnya proses pembelajaran dilaksanakan melalui tatap muka berubah menjadi pembelajaran online (daring).

Pengembangan pembelajaran secara online ini akan bertumpu kepada sumber daya manusia yaitu tenaga pengajar (Komariah, Kurniady, \& Rusdinal, 2019). (Prensky, 2001b) juga menyatakan masalah pembelajaran pada abad 21 terletak pada generasi pengajar yang lahir sebelum tahun 1980 yang disebut sebagai digital imigrant memiliki kemampuan yang berbeda dengan kebutuhan generasi yang lahir pada era digital yang disebut dengan digital native. Perbedaan itu terdapat pada karakteristik keterampilan penguasaan dan pemanfaatan teknologi informasi. digital imigrant juga dipandang memiliki ketergantungan yang berlebihan pada metodologi pengajaran yang lama yang dalam hal ini diartikan mengajar dengan mengunakan metode ceramah tanpa pengunaan teknologi (Koumachi, 2019). Menurut (Riegel \& Mete, 2017), Selama ini Digital Imigrant lebih suka interaksi langsung dari pada interaksi digital.

Berdasarkan latar belakang pada bahagian pendahulauan ini maka kami memandang penting dilakukan pelatihan kepada guru-guru tentang pelaksanaan pengintegrasian pendidikan alquran dan budaya alam minangkabau dengan matapelajaran disekolah. Artikel ini menjadi semakin menarik karena akan membahas langkah-langkah pelatihan untuk menyusun perencanaan pembelajaran yang mengintegrasikan dengan pendidikan alquran dan budaya alam minangkabau dengan setting pembelajarn daring.

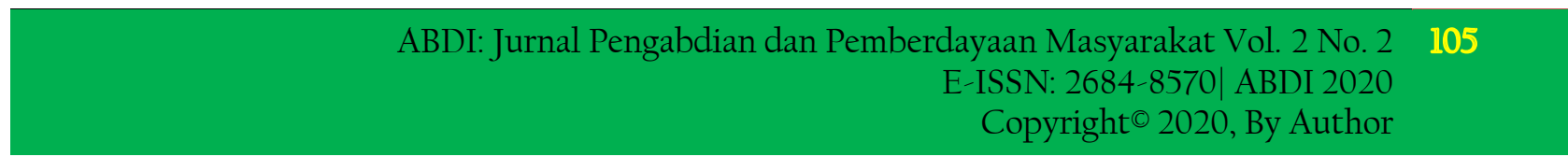




\section{Metode Pelaksanaan}

Artikel ini disarikan dari pelaksanaan pengabdian masyarakat tentang "Pelatihan Integrasi Pendidikan Al-Qur'an dan Budaya Alam Minangkabau dalam Mata Pelajaran Sosiologi kepada Guru Sosiologi se Provinsi Sumatera Barat". Sebagai yang terlihat pada judul pengabdian sasaran pengabdian ini adalah kelompok sosial yaitu organisasi profesi Guru Sosiologi yang bernama Musyawarah Guru Mata Pelajaran (MGMP).

Musyawarah Guru Mata Pelajaran (MGMP) merupakan suatu organisasi yang terdiri dari guru guru mata pelajaran yang sama dalam hal ini guru Sosiologi pada tingkat Sekolah Menengah Atas (SMA) yang berada di wilayah kabupaten Pesisir Selatan Provinsi Sumatera Barat. Dengan memberikan pemahaman dan keterampilan kepada Guru Sosiologi tentang integrasi Al-Qur'an dan Budaya Alam Minangkabau dengan matapelajaran Sosiologi maka diharapkan pendidikan karakter berbasis sosial budaya terlaksana sebagaimana tuntutan kurikulum 2013.

Kegiatan pengabdian kepada masyarakat ini dilaksanakan melalui seminar dan Workshop. Seminar yang akan dilaksanakan selama dengan rincian materi sebagai berikut: 1) Pembelajaran Abad 21 dan kompetensi Guru 2) Teori dan Prinsip pendidikan karakter berbasis sosial budaya 3) Nilai-nilai Alquran dan BAM untuk kepentingan pedagogis 4) Integrasi Alquran dan BAM dalam matapelajaran sosiologi, 5) Desain Pendidikan karakter. Kemudian pada saat Workshop akan dilaksanakan untuk membuat rencana pelaksanaan pembelajaran, Media dan Bahan Ajar sosiologi terintegrasi dengan pendidikan al-Qur'an dan Budaya Alam Minangkabau Evaluasi dari pelaksanaan setelah kegiatân dilaksanakan melalui evaluasi produk yang dibuat oleh guru-guru sosiologi.

\section{Hasil dan Pembahasan}

\section{Integrasi Pendidikan Al-Qur'an dan Budaya Alam Minangkabau dalam Matapelajaran}

Pendidikan karakter dapat dilaksanakan dengan strategi mengintegrasi nilai-nilai karakter dalam proses pembelajaran, pengembangan budaya sekolah, kegiatan pengembangan diri (Iayanan bimbingan konseling, bimbingan kelompok kecil dan kegiatan ekstrakurikuler). Pemerintah Provinsi Sumatera Barat seperti yang dijelaskan dalam Peraturan Gubernur Sumatera Barat Nomor 73 tahun 2013 dijalankan dengan cara integrasi pendidikan alquran dan Budaya Minangkabau dalam proses pembelajaran.

Berdasarkan kebijakan dari Gubernur Sumatera Barat tersebut. Pendidikan Al-Qur'an dan Budaya Minangkabau di Integrasikan pada mata pelajaran seperti Pendidikan Agama Islam, Bahasa Indonesia, Bahasa Inggris, Matematika, Kimia, Fisika, Biologi, Sejarah, Ekonomi, Geograsi, PPKn, PKWU/PKK, dan Penjaskes, Sosiologi, Seni dan Budaya (Dinas Pendidikan Provinsi Sumatera Barat, 2017). Penerapannya Integrasi dilakukan dengan dengan cara a) Pengintegrasian nilai-nilai karakter yang relevan dengan materi pembelajaran dalam Silabus, RPP (Rencana Program Pembelajaran), Bahan Ajar, lembar kerja peserta didik; b). Menerapkan nilai-nilai karakter dalam proses pembelajaran melalaui langkahᄀlangkah pembelajaran, yang meliputi: Pendahuluan; Kegiatan inti (eksplorasi, elaborosi dan konfirmasi), dan Penutup. c). Mengintegrasikan ayat-ayat al-Qur'an pada setiap materi dalam pembelajaran.

Dalam melaksanakan Integrasi Al-Qur'an dan Budaya Minangkabau dengan mata pelajaran ini sangat ditentukan oleh kompetensi Guru. Lebih lanjut, kompetensi yang harus dimiliki oleh guru dalam pelaksanaan pendidikan karaker ini adalah: Guru harus mampu memahami dengan baik kompetensi dasar yang akan diajarkan; Guru harus memiliki pengetahuan terkait dengan nilai-nilai budaya minangkabau dan kemampuan dalam menelusuri dan menafsir kandungan isi Alquran yang berkaitan dengan kompetensi dasar matapelajarannya; Guru harus mampu mengajar secara kontekstual yaitu mengaitkan bahan ajar dengan nilai Al-Qur'an dan Budaya Alam Minangkabau.

\section{Pelatihan pengintegrasian Pendidikan Alqur'an dan Budaya Alam Minangkabau.}

Berdasarkan hasil penelitian dari (Junaidi et al., 2020) bahwa pendidikan karakter berbasis sosial budaya yang dilakukan oleh pemerintah Provinsi Sumatera Barat dilaksanakan dengan program integrasi 
pendidikan Al-Qur'an dan Budaya Alam Minangkabau dengan matapelajaran di sekolah menengah atas. Proses pengintegrasian dengan matapelajaran pada prinsipnya tidak mengganggu substansi dari mata pelajaran. Lebih lanjut hasil penelitian (Eka Putri \& Fernandes, 2019) menemukan bahwa implemntasi dari program pendidikan karakter di Sumatera Barat belum terlaksana dengan baik. Dimana masih banyak Guru-guru yang belum memiliki pengetahuan dan keterampilan untuk melaksanakan program tersebut, adapun kendala pelaksanaannya adalah kemampuan Guru dalam membuat rencana pelaksanaan pembelajaran dan pengembangan materi ajar.

Keadaaan ini membuat kami melakukan kegiatan pelatihan pengintegrasian pendidikan Alquran dan Budaya Alam Minangkabau kepada guru-guru yang ada di Sumatera Barat. Adapun pelatihan dilakukan dalam dua tahapan pertama dalam bentuk seminar dan workshop. Kerangka kegiatan dapat dilihat pada tabel berikut tabel berikut ini:

\section{Tabel 1. Kerangka kegiatan Pelatihan}

\begin{tabular}{ll}
\hline No & \multicolumn{1}{c}{ Kegiatan } \\
\hline 1 Seminar \\
"Pembelajaran Abad 21 dan Keberlanjutan Pendidikan Karekter pada masa pandemi Covid- \\
19" \\
Materi Seminar \\
a. Pembelajaran Abad 21 dan kompetensi Guru \\
b. Teori dan Prinsip pendidikan karakter berbasis sosial budaya \\
c. Nilai-nilai Alquran dan BAM untuk kepentingan pedagogis \\
d. Integrasi Alquran dan BAM dalam matapelajaran sosiologi \\
e. Pendidikan karakter dalam Setting pembelajaran tatap muka \\
\hline 2 Workshop \\
Merancang Rencana pelaksanaan pembelajaran, Media dan Bahan Ajar sosiologi terintegrasi \\
dengan pendidikan al-Qur'an dan Budaya Alam Minangkabau.
\end{tabular}

Kegiatan pelatihan pengintegrasian telah dilaksanakan secara daring melalui pelatihan menggunakan Zoom Meeting. Berikut bentuk foto kegiatan seminar dan workshop integrasi pendidikan Al-Qur'an dan Budaya Minangkabau.
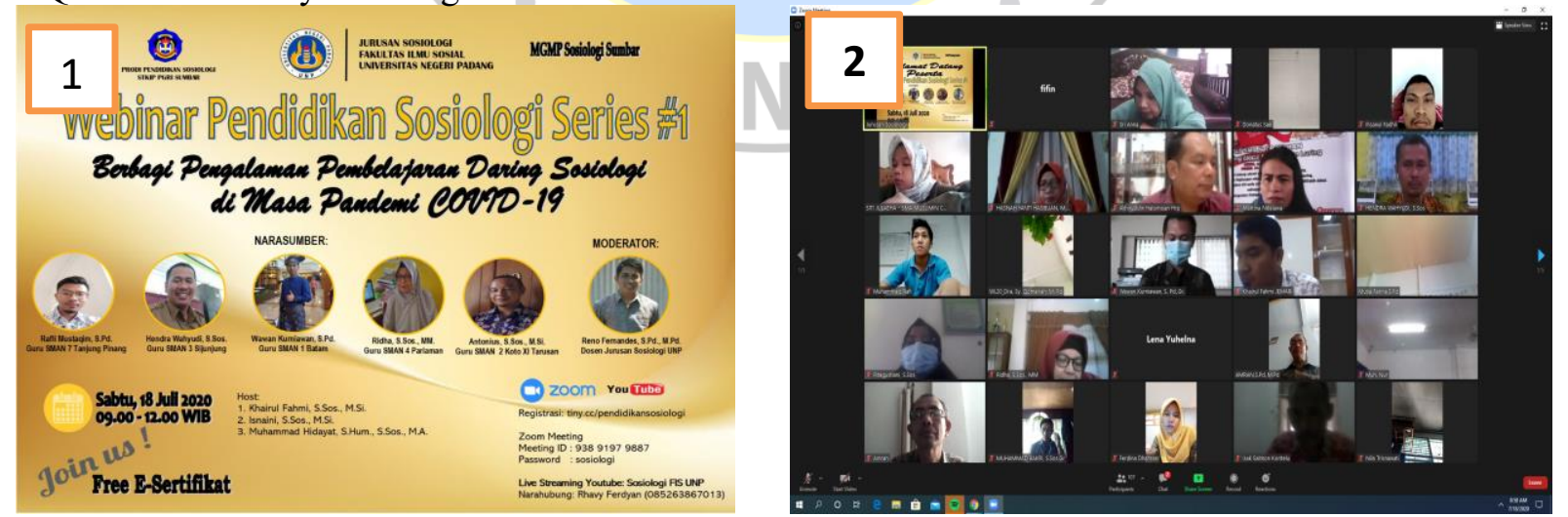

Gambar 1. Leaflet Kegiatan "Berbagi Pengalaman Pembelajarn Daring Sosiologi di Masa Pandemi Covid 19.2) Tampilan Zoom Meeting ketika seminar. 
Setelah seminar selesai dilaksanakan tahapan kegiatan selanjutnya yang dilaksanakan Workshop pembuatan rencana pelaksanaan pembelajaran, media pembelajaran dan materi ajar mata pelajaran sosiologi terintegrasi dengan pendidikan Al-Qur'an dan Budaya Alam Minangkabau. Pendampingan dan mentoring tersebut dilaksanakan selama satu bulan melalui media komunikasi Whatsapp Group. Hasil yang dicapai dari 30 orang peserta yang mengikuti pendampingan dan mentoring 25 orang atau $83 \%$ peserta berhasil membuat RPP, Media dan Materi Ajar sosiologi terintegrasi dengan pendidikan AlQur'an dan Budaya Alam Minangkabau dengan setting pembelajaran daring.

\section{Kesimpulan}

Pelatihan pengintegrasian pendidikan Al-Qur'an dan Budaya Alam Minangkabau dengan matapelajaran Sosiologi kepada Guru-guru Sosiologi se Sumatera Barat merupakan salah satu cara dalam rangka membuat program pendidikan karakter berbasis sosial budaya yang digagas oleh dinas pendidikan Sumatera Barat dapat mencapai tujuannya. Metode pelaksanaan dilakukan dengan dua tahapan diantaranya seminar dan workshop/mentoring pembuatan RPP, Media dan Materi Ajar Sosiologi terintegrasi dengan Pendidikan Al-Qur'an dan Budaya Alam Minangkabau. Berdasarkan evaluasi kegiatan pelatihan yang dilakukan dapat dikatakan berhasil karena setelah proses kegiatan dilaksanakan kegiatan dapat dikatakan berhasil karena dari 30 orang peserta yang mengikuti pendampingan dan mentoring 25 orang atau $83 \%$ peserta berhasil membuat RPP, Media dan Materi Ajar sosiologi terintegrasi dengan pendidikan Al-Qur'an dan Budaya Alam Minangkabau dengan setting pembelajaran daring.

\section{Daftar Pustaka}

Agustina. (2012). Pembelajaran Budaya Alam Minangkabau (BAM) sebagai Wadah Pelestarian Kearifan Lokal: antara Harapan dan Kenyataan. Komposisi: Jurnal Pendidikan Bahasa, Sastra, Dan Seni, 13(1). https://doi.org/10.24036/komposisi.v13i1.3926

Azoulay, P., Ding, W., \& Stuart, T. (2007). The determinants of faculty patenting behavior: Demographics or opportunities? Journal of Economic Behavior \& Organization, 63(4), 599-623.

Bowe, B. J., \& Wohn, D. Y. (2015). Are There Generational Differences? Social Media Use and Perceived Shared Reality. ACM International Conference Proceeding Series, 2015-July(July). https://doi.org/10.1145/2789187.2789200

Depiyanti, O. M. (2014). MODEL PENDIDIKAN KARAKTER DI ISLAMIC FULL DAY SCHOOL (Studi Deskriptif pada SD Cendekia Leadership School, Bandung). TARBAWY: Indonesian Journal of Islamic Education. https://doi.org/10.17509/T.V1I2.3769

Dewi, S., Listyowati, D., \& Napitupulu, B. E. (2018). Bonus Demografi Di Indonesia: Suatu Anugerah Atau Petaka. Journal Of Information System, Applied, Management, Accounting And Research, 2(3), 17-23.

Eka Putri, Y., \& Fernandes, R. (2019). Pelaksanaan Integrasi Pendidikan Karakter Nilai Al-Qur'an dan Nilai Budaya Alam Minangkabau Dalam Pembelajaran Sosiologi (Studi Kasus: SMA Negeri 2 Padang dan SMA Adabiah Padang). Jurnal Sikola: Jurnal Kajian Pendidikan Dan Pembelajaran. https://doi.org/10.24036/sikola.v1i1.8

Fajarini, U. (2014). Peranan Kearifan Lokal dalam Pendidikan Karakter. SOSIO DIDAKTIKA: Social Science Education Journal. https://doi.org/10.15408/sd.v1i2.1225

Fernandes, R. (2019). Relevansi Kurikulum 2013 dengan kebutuhan Peserta didik di Era Revolusi 4.0. SOCIUS. https://doi.org/10.24036/scs.v6i2.157

Junaidi, Susilawati, N., Fernandes, R., Sylvia, I., \& Putra, E. V. (2020). Integration of Al-Quran Education and Minangkabau Culture on Subjects in Formal Schooling. https://doi.org/10.2991/assehr.k.200217.029 
Komariah, A., Kurniady, D. A., \& Rusdinal. (2019). The relationship between the role of a principal and quality of school academic service: The mediating function of teacher commitment. International Journal of Innovation, Creativity and Change, 9(3), 19-34.

Koumachi, B. (2019). "Digital Natives" Mythbusted The Digital Turn in Higher Education: "Digital Natives" Mythbusted. International Journal of Technology in Education and Science (IJTES), 3(1), 56-62. Retrieved from www.ijtes.net

Kristiawan, M. (2016). Filsafat Pendidikan The Choice Is Yours. Yogyakarta: Valia Pustaka.

Li, Y., Wang, Q., \& Lei, J. (2020). Exploring Technology Professional Development Needs of Digital Immigrant Teachers and Digital Native Teachers in China. International Journal of Information and Communication Technology Education, 16(3), 15-29. https://doi.org/10.4018/ijicte. 2020070102

O'Bannon, B. W., \& Thomas, K. (2014). Teacher perceptions of using mobile phones in the classroom: Age matters! Computers and Education, 74, 15-25. https://doi.org/10.1016/j.compedu.2014.01.006

Prensky, M. (2001a). Digital Native, Digital Immigrant Part 1. On the Horizon, 9(5), 1-6.

Prensky, M. (2001b). Digital Natives, Digital Immigrants. MCB University Press, 9(5), 1-6.

Priyatna, M. (2017). Pendidikan karakter berbasis kearifan lokal. Edukasi Islami: Jurnal Pendidikan Islam, 5(10).

Puspito, D. W. (2017). Implementasi Literasi Digital Dalam Gerakan Literasi Sekolah. Konferensi Bahasa Dan Sastra (International Conference on Language, Literature, and Teaching) II.

Ransdell, S., Kent, B., Gaillard-Kenney, S., \& Long, J. (2011). Digital immigrants fare better than digital natives due to social reliance. British Journal of Educational Technology, 42(6), 931-938. https://doi.org/10.1111/j.1467-8535.2010.01137.x

Riegel, C., \& Mete, R. (2017). Educational Technologies for K-12 Learners: What Digital Natives and Digital Immigrants Can Teach One Another. Educational Planning, 24(4), 49-58.

Rosyidah, F. N., \& Nurdin, M. F. (2018). Media Sosial: Ruang Baru dalam Tindak Pelecehan Seksual Remaja. Sosioglobal: Jurnal Pemikiran Dan Penelitian Sosiologi, 2(2), 38-48.

Rosyidah, S. K. (2017). PENGARUH GLOBALISASI DALAM PERKEMBANGAN PERJUANGAN IDENTITAS DAN HAK KELOMPOK LGBT DI INDONESIA. Global Dan Policy, 5(02).

Subandowo, M. (2017). Peradaban dan Produktivitas dalam Perspektif Bonus Demografi serta Generasi Y dan Z. SOSIOHUMANIKA, 10(2), 191-208.

Viner, R. M., Russell, S. J., Croker, H., Packer, J., Ward, J., Stansfield, C., ... Booy, R. (2020). School closure and management practices during coronavirus outbreaks including COVID-19: a rapid systematic review. The Lancet Child \& Adolescent Health, O(0), 397-404. https://doi.org/10.1016/S2352-4642(20)30095-X 